\title{
New method to identify and map flagship fleets for promoting conservation and ecotourism.
}

\begin{abstract}
Evaluating flagship species and their potential for biological preservation and ecotourism development is a key issue for many audiences within the conservation and social fields. Despite several methods available to identify flagships, their application is often constrained in remote, poorly studied regions. Developments are needed in statistical and spatially-explicit approaches to assess species' traits influencing flagship appealing, to identify flagship fleets, and to map the location of flagship hotspots. Here, we developed a new method to identify flagship species in regions with knowledge gaps, using a two-stage statistical approach (ordination and clustering algorithms) to assess variable's contribution to appealing and to group species sharing similar characteristics into flagship fleets. We then mapped areas concentrating the highest richness of flagships. Unique morphologies and behaviours, conservation status, endemicity, body size and weight, and feeding habits were the traits contributing the most to the flagship appealing. Nine flagship fleets were identified, from which two were the most suitable for conservation marketing and ecotourism promotion campaigns in Sahara-Sahel: Fleet A comprising 36 large-bodied species and Fleet B including 70 smallbodied species. A total of 20 hotspots were identified for large-bodied flagships and 10 hotspots for small-bodied flagships. The methodology was suitable to identify flagship species for conservation marketing and for developing ecotourism operations in the Sahara-Sahel, to independently assess which species' traits are relevant for flagship appealing, and to organise fleets for multispecies-based marketing campaigns. The framework is scalable and replicable worldwide.
\end{abstract}

Keywords: Charismatic species; cluster analysis; deserts; flagship fleets; flagship hotspots; principal component analysis. 


\section{Introduction}

Flagship species are defined as "a species used as the focus of a broader conservation marketing campaign based on its possession of one or more traits that appeal to the target audience" (Veríssimo et al., 2011), serving as symbols to stimulate conservation awareness and action, drawing financial support to protect habitats and other species (Simberloff, 1998). Despite several reinterpretations by academics (Barua, 2011), the latest definitions focus on the strategic, socio-economic, and marketing character of the concept (Veríssimo et al., 2011; Walpole \& Leader-Williams, 2002). Flagship species act as a marketing (the process of planning and executing the value and distribution of products and services between organizations and target audiences) strategic tool to influence target audiences' preferences and behaviours for the benefit of conservation efforts, by placing them at the core of the marketing process (see Wright et al., 2015 for a full review). Thus, they have been used in conservation awareness (Veríssimo et al., 2009), fundraising (Clucas et al., 2008), ecotourism (Walpole \& Leader-Williams, 2002) and community-based conservation initiatives (Barua et al., 2011), in the protection of species and habitats (Smith et al., 2012), in policy making (Jepson \& Barua, 2015), and in the development of pro-conservation behaviours (Smith \& Sutton, 2008). Flagship fleets were recently developed as a tool to group several species into one single, more successful, flagship marketing campaign. Thus, they can raise the profile of more than one species and benefit a wider range of biodiversity (Barua et al., 2011; Veríssimo et al., 2014), while ensuring that multiple stakeholder groups' preferences (e.g. of desert ecotourists; avitourists; 'Big-Five' tourists; academics; conservationists; international NGOs) are covered in flagship campaigns (Di Minin et al., 2013; Lidsey et al., 2007). Flagship fleets were proposed to answer concerns regarding fund diversion from less to high charismatic species (e.g. Andelman \& Fagan, 2000 and Joseph et al., 2011) and to lead behavioural change within and between different audiences (Root-Bernstein \& Armesto, 2013). Pooling species belonging to different taxonomic groups into one single fleet can help targeting the desires of different audiences, thus maximizing the return-on-investment in multiple-species conservation efforts (Veríssimo et al., 2014).

Many criteria for selecting flagship species have been proposed (Bowen-Jones \& Entwistle 2002) but selection is mostly based in morphological, behavioural and cultural traits that are likely to be appealing to the planned target audience (Batt, 2009; Barua et al., 2011, 2012; Veríssimo et al., 2009, 2011). These typically include, amongst others, body size, endemicity level or conservation status A key aspect in flagship choice is the extent to which it builds attitudinal, behavioural, financial or political support, without which their effectiveness as flagships may be compromised (Veríssimo et al., 2011). Thus, flagship species can be selected according to different methodologies, following social marketing, environmental economics, or conservation biology objectives (Veríssimo et al., 2011). In the past, they were selected mostly based on charisma, i.e. cultural value, rather than on objective principles (Home et al., 2009). Several conservation initiatives selected flagships for marketing campaigns based on preconceptions about the types of species favoured by the public, including potential tourists, conservationists, and academics. However, in conservation marketing, product familiarity is critical to consumer preference and any research on flagship preferences should take into account the knowledge level of the audience for properly identifying flagships (Garnett et al. 2018). To overcome this issue, choice experiment (CE) approaches have been developed to identify flagships for ecotourism promotion and conservation marketing campaigns (e.g. Di Minin et al., 2013; Veríssimo et al., 2009, 2013). These tools are derived from marketing theory and explore how particular attributes of a product are valued (Brown, 2010) and capture the heterogeneity of respondents preferences towards biodiversity attributes (Di Minin et al., 2013; Hausmann et al., 2016; Naidoo \& Adamowicz, 2005). However, to be informative, CE relies on the principle that the public is well informed about the available species diversity in a given area to take a decision about attractiveness. Understanding people's preferences towards every possible option from a large species pool may be an impractical task and even be unfeasible in remote regions with knowledge gaps about local biodiversity (Veríssimo et al., 2009). Photography-based studies have been used to address this shortcoming (e.g. Macdonald et al., 
2015, 2017), but confounding effects of differing photograph colouration and angle have been raised (Batt, 2009), suggesting that flagship selection needs methodological developments that allow refining the identification of suitable species for different flagship campaigns in regions where the public is not well informed about the local biodiversity (Garnett et al., 2018). Furthermore, the contribution of species traits to flagship appealing in CE approaches is evaluated only after respondents have chosen their preferred species, which is only possible in well-studied regions. In remote regions, non-heuristic methods using multi-criteria in large datasets of species may allow evaluating the suitability of a species for the development of conservation marketing and ecotourism campaigns (Veríssimo et al., 2011). Non-heuristic methods, such as Principal Component Analysis (PCA), depend only on the dataset traits to assess variables contribution, whereas heuristic methods are affected by the subjective judgments of individuals that can lead to different, even antagonist answers to the same question (Pathak et al., 2017). Unsupervised learning methods, such as Cluster Analyses, are used to group a set of objects (e.g. species) based on the observed values of several variables for each individual object (e.g. Batt, 2009), in a way that objects in the same group are more similar to each other than to those in other groups (Tryon, 1939). The potential of non-heuristic methods has been successfully explored in grouping water-bodies with similar traits for ecotourism development (e.g. Santarém et al., 2018) or in bioregionalization exercises based in environmental variation and species distribution (e.g. Brito et al., 2016). Non-heuristic methods have the potential to eliminate biases from analytical processes (Batt, 2009) and thus may help identifying flagship fleets efficiently.

In developing nations, often rich in endemic biota but lacking common charismatic megafauna (large-sized vertebrates; Hausmann et al., 2016), international ecotourism can be highly beneficial for the national gross domestic product and local development (UNESCO, 2003; Twining-Ward et al., 2018; Weaver, 2001). This is the case of Sahara-Sahel range countries in Africa that are categorised as low human development (Brito et al., 2014) and are underfunded for poverty alleviation and biodiversity loss retention schemes (Durant et al., 2012; Waldron et al., 2013), display extensive remote areas, lack large populations of common African flagship species (e.g. elephant, lion) but are rich in endemic vertebrates (Brito et al., 2016). Ecotourism campaigns have been set as regional conservation priorities (Brito et al., 2016; Hosni, 2000), but detailed knowledge about biodiversity levels in the Sahara-Sahel is still limited (Brito et al., 2014), as well as people's understanding of the local potential flagship species. Effective methodologies are needed to identify flagship species in contexts of endemic-rich desert developing countries lacking common flagships and exhibiting biodiversity knowledge gaps (Santarém \& Paiva, 2015).

Mapping the location of flagship hotspots, i.e. particular areas concentrating exceptional flagship species richness suitable for conservation marketing and ecotourism promotion (adapted from Marchese, 2015), is in need of development. These areas are defined by one or more species-based metrics (e.g. species richness, number of species restricted to a particular area, or functional diversity within the ecosystem) in order to protect species supporting unique roles (Marchese, 2015). Despite the potential to indicate the location of suitable regions to allocate flagship-based conservation initiatives and to positively influence public behaviour through biodiversity, mapping the richness of flagship species or flagship fleets remains unexplored. Species abundance data is scarce in Sahara-Sahel (Brito et al., 2014, 2016) but mapping hotspots in such desert areas would help setting priorities for ecotourism development and conservation, which is highly relevant for such poorly known areas and for minimizing local species extinction (Vale et al., 2015; Durant et al. 2014).

Here, we propose a systematic method to identify flagship species in regions where the public is not well informed about the local species diversity and where CE would be impossible to perform to identify flagships, using Sahara-Sahel vertebrates as case-study. We first assess objectively which species traits drive flagship appealing, then assess which fleets of species can be used in flagship campaigns, and finally map flagship hotspots. Particularly, we want to answer the following questions: 1) Which species' traits contribute the most to explain species' flagship appealing?; 2) How many flagship fleets can be distinguished according to their shared characteristics to flagship suitability?; 3) Which flagship fleets display potential characteristics 
for conservation marketing and ecotourism promotion campaigns?; and 4) Where are located appearance, likelihood of extinction and endemicity are the most relevant traits for flagship selection in the Sahara-Sahel; 2) the most important variables will help shaping flagship fleets given the variabilities in those traits; 3 ) species displaying similar traits will tend to be clustered together and form different fleets suitable for distinct conservation marketing and ecotourism promotion campaigns; and 4) flagship hotspots will generally tend to be concentrated in local biodiversity hotspots and will tend to spatially overlap hotspots of total species richness.

\section{Methods}

\subsection{Study area}

Includes the Sahara and the Sahel $\left(\approx 11,200,000 \mathrm{~km}^{2}\right.$ ) ecoregions (Dinerstein et al., 2017; Appendix C) and comprises 4072 grid cells of 0.5 degree resolution (WGS84 coordinate reference system).

\subsection{Species list and trait data}

The list of continental vertebrates of the Sahara-Sahel and their distribution polygons was retrieved from IUCN (2017), and updated according to Brito et al., $(2018,2016)$. It comprises 1,126 species, including 52 amphibians, 188 reptiles, 584 birds, and 302 mammals (Appendix F). For each species, we collected data on 13 variables related to distributional variation, morphophysiological and behavioural characteristics, conservation status, and cultural representation, based on relevant literature and other sources (see Appendix A). The variables were:

1) Area of occupancy (AOC): the size of the geographical distribution of the species under analysis has been suggested as a key criterion for the selection of flagship species, as species with narrow ranges can reinforce allegiance with the region and influence people's willingness to pay for conserving low distributed animals, while large ranged species help promoting global priority areas (Barua et al., 2011; Bowen-Jones \& Entwistle 2002; Root-Bernstein \& Arnesto, 2013; Veríssimo et al., 2013). Using a Geographical Information System (GIS; ESRI 2012), we calculated the area of occupancy as the area within a species extent of occurrence (area contained within the minimum convex polygon encompassing the known species locations) that is occupied by that species (IUCN 2017);

2) Body size (BSIZE) and 3) body weight (BWEIG): these traits have been extensively used in other flagship selection studies, as larger sizes and weights usually influence the easiness to observe species in the wild and animal attractiveness (Barua et al., 2012; Clucas et al., 2008; Ebner et al., 2016; Home et al., 2009; Macdonald et .al., 2015, 2017; Smith et al., 2012; Veríssimo et al., 2014). We quantified the maximum body size (total length, TL) and the maximum weight irrespectively of sexual dimorphism in these variables (sexual differences in measurements were not considered; we recorded only the longest body length and the largest weight value of the two sexes);

4) Morphologies (MORPH) and 5) behaviours (BEHAV): species exhibiting unique characteristics are highly valued by the public (Jepson \& Barua 2015; Macdonald et al., 2015; Root-Bernstein \& Armesto, 2013; Veríssimo et al., 2009). We accessed morphological - such as keeled scales and tuft of hair on ears to protect against sand - and behavioural adaptations - such as sand swimming and adapted feathers to transport water - to local desert environments, as a proxy for these uniqueness's; 6) Number of colours (NCOL) and 7) colour patterns (COLPAT): species with complex body colorations and recognizable colour patterns are considered more appealing to international audiences (Batt, 2009; Barua et al., 2012, 2011; Macdonald et al., 2015). We quantified the maximum number of colours and colour patterns, irrespectively of ontogenetic shits and sexual dimorphism. For coloration, we considered 10 basic colour schemes (white, black, yellow, green, blue, orange, grey, red, brown, and purple). For body pattern, we considered main patterns - uniform, patches, spots, and stripes (longitudinal or transverse bars) - and then 
quantified the cumulative number of patterns in each species: three (patches + spots + stripes), two (e.g. spots + stripes), one of those, or none (see Appendix D for examples);

8) Conservation status (CS): likelihood of extinction of a species has been extensively explored within the flagship literature, because threatened species urge the development of international conservation campaigns to attract conservation funds and ecotourists are seen as the mean to attract the money needed (Barua et al., 2011; Bowen-Jones \& Entwistle 2002; Clucas et al., 2008; Ebner et al., 2016; Macdonald et al., 2015, 2017). Species conservation statuses were based on IUCN Red List of Threatened Species (IUCN 2017). The Scimitar-horned Oryx (Oryx dammah) was considered in this study as Extinct in the Wild, following IUCN categories, but the species has been recently reintroduced in Chad (Brito et al., 2018);

9) Endemicity (END): species with restricted distribution provide symbols of regional and national adherence and reflect strong local identity (Bowen-Jones \& Entwistle 2002; Takahashi et al., 2012; Veríssimo et al., 2009, 2014). Species were categorised as endemic from the Sahara-Sahel or as non-endemic (if the distribution covered areas outside the Sahara-Sahel); 10) Daily (ACTIV) and 11) seasonal (SEAS) activities: the easiness to observe a species is influenced by its daily and seasonal activity patterns (Macdonald et al., 2015; Root-Bernstein \& Armesto, 2013; Veríssimo et al., 2013, 2009). Species that are easy to spot in the wild are usually preferable as flagships in comparison to others less conspicuous (Reynolds \& Braithwaite 2001). We accessed daily activity by considering the species as being diurnal, nocturnal or cathemeral (day and night activity). We assessed species seasonal activity by evaluating if the species is sedentary (constantly present in the study area) or seasonal (exhibiting migratory movements and thus not available all year round);

12) Feeding habits (FEED): different species feeding habits attract distinct types of audiences that feel linked to one or another diet type (Ebner et al., 2016). Usually, carnivores are preferred by people who are raising the profile of potential flagships (Clucas et al., 2008; Macdonald et al., 2015, 2017). The trophic levels we considered were: carnivore (meat-eating, including arthropods and fishes), herbivore (vegetation protein-eating), omnivore (vegetation, fruit, seed, grain, and/or nectar and animal protein-eating), frugivore (fruit, seed, grain and/or nectareating), and necrophage (carrion-eating);

13) Cultural, religious and medical uses (CRM): the cultural significance of a species is a major characteristic to be foreseen in a flagship. Relationships to local art, folklore and handicraft, or uses of venoms for medical, or religious representations are highlighted in flagship species (Barua et al., 2012; Bowen-Jones \& Entwistle 2002; Takahashi et al., 2012). We evaluated where species have any of those cultural, religious and/or medical uses described above and treated this as a binomial variable (yes or no).

\subsection{Statistical analyses}

We applied two procedures to identify which traits are contributing the most to the appealing character of species for flagship marketing (see Appendix B for details). First, we performed a PCA for mixed (numerical and categorical) data (PCAmix), after standardised the numerical data, and then applied an orthogonal rotation to the PCA loadings (Chavent, Kuentz-Simonet, \& Saracco, 2012). Contribution of variables is given by the squared loadings (correlation coefficients) of species traits with the first two rotated axes of the PCAmix. Squared loadings are the squared correlation for numerical variables and the correlation ratios for categorical variables with the rotated components, respectively (Chavent et al., 2017b, 2012).

Flagship fleets, i.e. groups of species sharing similar characteristics for different flagship-based marketing campaigns, were identified using a model-based clustering approach (Scrucca et al., 2016). Fourteen multivariate normal mixture models with different parameterizations concerning the distribution, volume, shape and orientation of the covariance matrix of the multivariate data of the species were estimated by maximum likelihood using an expectationmaximization algorithm. The best model and the optimum number of clusters were chosen using the Bayesian Information Criterion (BIC) applied to the two first rotated axes of the PCAmix. The optimum number of clusters defined the number of different flagship fleets and for each cluster we matched a flagship fleet (Appendix E). 
All analyses were performed in R version 3.4.3, using the functions PCAmix and PCArot of the MClust package (Scrucca et al., 2016) for flagship fleets quantification.

From the groups identified in the clustering analysis, we identified which ones are the most interesting flagship fleets for conservation marketing and ecotourism promotion campaigns. The identification of these fleets were based on the presence of traits (such as body size/weight, endemism, conservation status or unique adaptations; Clucas et al., 2008; Veríssimo et al., 2009, 2013) in the species that belong to each identified flagship fleet and that are commonly appreciated by different audiences (e.g. desert ecotourists; avitourists; academics; conservationists).

\subsection{Mapping flagship hotspots}

To identify and map flagship hotspots of the selected fleets for conservation marketing and ecotourism promotion campaigns, we first intersected species distribution polygons with grids of 0.5-degree resolution to generate matrices of species presence/absence by grid cell in a GIS. A species was considered to occur in a cell if any portion of the species' range overlapped the cell. Then, flagship hotspots for each of the fleets were obtained by summing the number of flagship species occurring in each grid cell. In order to identify the areas that maximize the likelihood of observing flagships belonging to multiple fleets, the distributions of retrieved fleets were overlapped to generate the combined flagship hotspots, representing $50 \%$ of the richness of each of the two groups. Protected areas network (IUCN \& UNEP-WCMC, 2018) was overlapped with the flagship hotspot map to identify gaps in the representation of hotspots in currently protected areas.

\section{Results}

\subsection{Traits driving flagship appealing}

Several variables contributed to the flagship appealing: unique morphologies and behaviours, conservation status and endemicity on the first dimension of the PCAmix, and body size, body weight, conservation status and feeding habits on the second dimension. The two first dimensions accounted for $17.23 \%$ of the variability (Table 2; Fig. 1).

\subsection{Identification of flagship fleets}

The model with the highest BIC value (Appendix E) was selected to identify the number of flagship fleets. The BIC increased with the number of clusters and reached the plateau at nine clusters, which was chosen as the optimum number of flagship fleets. Some groups were more cohesive than others (e.g. fleet $\mathrm{H}$ is very cohesive while fleet $\mathrm{A}$ is heterogeneously dispersed along the two dimensions; Fig. 2), due to the weight of each species traits on grouping species into flagship fleets (Fig.1). Each flagship fleet displays distinct characteristics potentially suitable for different flagship-based conservation and ecotourism initiatives and audiences' preferences (Appendix F).

\subsection{Suitability of flagship fleets for conservation and ecotourism campaigns}

From the nine flagship fleets identified, fleets A and B were the most suitable for conservation and ecotourism campaigns in Sahara-Sahel (Fig. 2). Group A ( $\mathrm{N}=36$ species), hereafter designated as large-bodied flagships, included mostly large and heavy mammals (18 species; e.g. Addax nasomaculatus) and reptiles (18 species; e.g. Uromastyx nigriventris), approximately half of them are regional endemics and exhibited some unique desert adaptations, more than a half is threatened with extinction, and most are herbivorous (Table 3). Group B ( $\mathrm{N}=70$ species), hereafter designated as small-bodied flagships, includes small and light birds (10 species; e.g. Passer luteus), mammals (six species; e.g. Ctenodactylus vali) and reptiles (54 species; e.g. Acanthodactylus aureus), most are regional endemics, exhibit several desert adaptations, are not threatened, and are carnivorous. In total, $7.8 \%$ of mammals, $36 \%$ of reptiles, and $1.7 \%$ of birds 
occurring in the Sahara-Sahel were identified as flagships, whereas no single amphibian was identified.

\subsection{Flagship Hotspots}

A total of 19 hotspots were identified for large-bodied flagships (regions number 1, 2, 3, 4, 6, 7, $8,9,10,11,12,13,14,15,16,17,19,20$, and 21 in Appendix C) and 16 hotspots for smallbodied flagships (regions number 1, 5, 7, 8, 9, 10,11,12, 13, 14, 15, 16, 17, 18, 20, and 21 in Appendix C). The combined map for large- and small-bodied flagships indicates the presence of flagship hotspots for both fleets combined in the mountains of Aïr, Hoggar, Tassili n'Ajjer and Mauritania, the Grand Erg Occidental, the Complex of Chotts, and the Nile River valley, and in sections of the Eastern Mountains, of the rivers White Nile, Niger and Senegal, and of the Western Corridor (see Appendix C for details). In both groups, flagship hotspots were located in particular Sahara-Sahel regions, such as mountains and waterbodies and are poorly overlapped by the current protected areas network (Fig. 3; Appendix C).

\section{Discussion}

\subsection{Methodological improvements from previous approaches}

The two-step statistical approach here used, allowed the identification of flagship species and fleets in a systematic way. By assessing statistically which species traits contribute to flagship appealing, we answered researchers' call for effective flagship evaluation methods that avoid biases inherent to people's responses to questionnaires (Home et al., 2009; Veríssimo et al., 2011). Our approach is independent from questionnaire-based assessments, which would be impractical in the Sahara-Sahel anyway, as many species are unknown to the public but may display currently hidden characteristics suitable for flagships (Smith et al., 2012). The use of PCA with mixed data allowed assessing the contribution of numerical and categorical variables and improved the evaluation of traits contributing to flagship appeal. The use of clustering algorithms allowed identifying several flagship species sharing similar characteristics (Batt, 2009) that can be used in multispecies-target campaigns, extending the benefits of future marketing campaigns to a wider range of biodiversity (Veríssimo et al., 2014).

The identification of flagship fleets considered all taxonomic groups together. The alternative strategy, analysing each taxonomic group individually, would likely inflate the importance of traits inside each taxonomic group that do not necessarily represent attractiveness in the real world. In the Sahara-Sahel, for instance, the area of occupancy for amphibians is a pointless variable due to the general desert environment of the region where few waterbodies are available to find them. Taxonomy-based analyses may also deflate the importance of traits that are commonly selected as attractive in real world situations identifying flagships (see below 4.3). Pooling taxonomic groups onto the analysis allowed the statistics finding which are the most variable traits and how many fleets can be defined based on their intrinsic traits, thus not biasing (inflating or deflating) traits by taxonomic group and answering the need to identify flagship species objectively and independently of the taxonomic group to which they belong to (Santarém \& Paiva, 2015; Veríssimo et al., 2014). Moreover, by pooling all taxa indiscriminately of their taxonomic group, we increased the chances of targeting higher number of different audiences at the same time, which may benefit a wider range of biodiversity (Di Minin et al., 2013; Hausmann et al., 2016).

The use of GIS approach allowed mapping the location of flagship hotspots, which may guide the implementation of flagship-based conservation initiatives. The methodology can be extrapolated to other biomes and the spatial approach here used constitutes a novel method that should be further explored in ecotourism-based research (Santarém et al., 2018).

\subsection{Potential methodological improvements for future works}

The method here used to identify flagship hotspots contains some potential caveats. Including variables associated with the perceptions of local people about flagships may improve flagship identification. For instance, species unlinked with human-wildlife conflicts may be 
acknowledged as important flagships, while crop-damaging species or that kill humans may be difficult to promote as flagships with positive symbolic value (Barua, Tamuly, \& Ahmed 2010). The ecological and economic roles (e.g. pollination and food provision, respectively), and population size (as a proxy for rareness) may also catalyse conservation actions efficiently (Barua et al., 2011; Ebner et al., 2016; Veríssimo et al., 2009).

Supervised machine-learning methods (Kotsiantis, 2007) can be used as alternative to the clustering method here applied to identify flagships. Based on a training set of successful flagship species together with species with low public appeal, models are trained to classify any species as flagship or not. Still, knowledge about the species under analysis must be available for effective method application (Smith et al., 2012).

Given the general paucity in the availability of accurate biodiversity distribution data in the Sahara-Sahel (Brito et al., 2014), the mapping of flagship hotspots was based in IUCN species distribution polygons. IUCN polygons depict the species full extent of occurrence and naturally include non-occurrence areas within the range, which probably inflated the rate of false presences (e.g. Graham \& Hijmans, 2006) and introduced omission and commission errors (Macdonald et al., 2017). In contrast, the most remote areas of the Sahara-Sahel or the areas subjected to long-term local conflicts are likely under sampled (Brito et al., 2016), which probably impacted the accuracy of the final mapped results. For instance, the combined map also demonstrates a completely absence of flagship hotspots in Libya and Chad and a poor representation in Sudan (Fig. 3). Additional research in these regions may dictate a different pattern, particularly in the data deficient Sudanese mountainous areas (Siddig, 2014), which may follow the general trend of flagship hotspots to be located in mountains (see Fig. 3 and Appendix $\mathrm{C}$ together). Although these constraints may cause some bias for the identified flagship hotspots due to deficient data, these effects were diluted when applying a coarse spatial resolution (pixel size of 0.5 degrees). Still, future developments should target the use of accurate distribution data, for instance by deriving species ranges from ecological niche-based models. Additionally, the spatial and temporal dynamics of many flagships, such as migrating birds or hibernating reptiles, should be contemplated in future developments, as these influence the likelihood of species observation and consequently the location of flagship hotspots.

\subsection{Factors relevant for assessing flagship species in deserts}

When identifying flagship species, there are species traits that are highly related. For instance, endemic species tend to display unique adaptations to deserts and large species are generally heavy (see correlations in axes XX and YY in Fig.1, respectively). These relationships helped to systematically build inferences on what characteristics are relevant for flagship appealing when applying statistical methods, as we did here.

Adaptations to deserts were relevant features in defining flagships in Sahara-Sahel (Fig. 1, Table 2), a finding similar to what was found in a study developed in Seychelles (Veríssimo et al., 2009), where species with unusual characteristics were selected by respondents.

International tourists and ecotourism operators often prefer species with unique adaptations to the local environment as they turn out to be regional mottos where they live and hence can raise funds more efficiently than others without particular adaptations (Root-Bernstein \& Arnesto, 2013; Veríssimo et al., 2009).

Similarly, endemism stands out as an important feature for desert flagship species. Endemism was selected by local communities as an important feature for potential Brazilian flagships (Veríssimo et al., 2014), although tourists did not find it an important trait for Indian flagships (Takahashi et al., 2012). Rarity is also an attractive trait to the public that is willing to pay additional fees for ecotourism and conservation projects targeting endemic species (Veríssimo et al., 2009). This is an encouraging result for endemic-rich areas, such as Sahara-Sahel, composed by several developing countries where flagship-based ecotourism can have a positive role (Brito et al., 2016, 2014).

Body size and weight helped defining flagship species in Sahara-Sahel. Fascination with large animals is widely reported as a key-element in defining flagship appeal (Macdonald et al., 2015, 2017) and large and heavy animals are also preferred by international NGOs when implementing flagship-based conservation programmes (Clucas et al., 2008). However, even 
small-sized flagships are acknowledged by specific target groups of tourists (Ebner et al., 2016; identified flagship fleets in the Sahara-Sahel (fleet A - large-bodied flagships and fleet $B$ small-bodied flagships; Figure 2, Appendix F). Hence, even the smallest animals can be used in flagship marketing campaigns if they exhibit traits that make them appealing flagships (Smith et al., 2012). For instance, the small-bodied flagships fleet is composed by species that display many unique adaptations to deserts, such as the reptiles of genera Acanthodactylus, Cerastes, and Scincus, which may be preferred by specialized audiences in deserts (e.g. desert ecotourists and conservationists) and targeted for specialized desert marketing campaigns (Santarém et al., 2018).

Likelihood of extinction was also found to be highly associated to species with flagship characteristics in the Sahara-Sahel. This kind of 'last chance to see' tourism is typical for various ecotourism destinations with rapidly changing habitats (Lemelin, Dawson \& Stewart, 2012) and as a phenomenon it is supported by many studies (e.g. Batt, 2009; Clucas et al., 2008; Ebner et al., 2016; Macdonald et al., 2015), which contrasts with the unimportance found in some works (e.g. Macdonald et al., 2017 and Smith et al., 2012). Notwithstanding, nonthreatened species may still be suitable for flagship marketing campaigns, as common species may be promptly chosen as regional ambassadors by local communities when compared to infrequently encountered rare species (Takahashi et al., 2012). This has implications for SaharaSahel species, as many of them are not threatened or have not been yet evaluated (Brito et al., 2016).

\subsection{Factors potentially relevant for defining flagship species in other biomes/scales}

Several species traits were identified as less important in defining flagship species in the SaharaSahel but may be relevant in other biomes (e.g. tropical jungles) or other scales of analysis (e.g. local, national). Although area of occupancy was one of the least important variables in this study, a pattern consistent with findings of other works, still, it is widely accepted that species with narrow ranges can reinforce local allegiance and influence people's willingness to pay for conserving low distributed animals, while large-ranged species help promoting global priority regions (Barua et al., 2011; Bowen-Jones \& Entwistle, 2002; Root-Bernstein \& Armesto, 2013; Veríssimo et al., 2013, 2009). Thus, distribution patterns should be contextualized when identifying flagship species in different biome/scale contexts, as conservation problems may vary accordingly.

Despite we were unable to find a grouping pattern by diet, carnivores are generally preferred by international ecotourists and wider audiences, as people not facing wildlife damages generally revere them (Clucas et al., 2008; Macdonald et al., 2017). However, other feeding habits may be preferred by specific audiences and thus this needs to be further contextualized in order to consider different preferences.

Body patterns were not important for many people from different regions of the world in a global assessment (Macdonald et al., 2015). However, striking colour patterns have been found as an important attribute of flagship appealing in other taxonomic groups, namely invertebrates (Barua et al., 2012). Unusual colour patterns may attract specific audiences as well, and thus deserve to be contextualized, as people from different context may differ in their preferences towards coloration and body patterns (Macdonald et al., 2015).

Visibility traits followed similar results in bird flagships assessments (Veríssimo et al., 2009). This contrasts with the recommendations to use such feature in wildlife tourism, where diurnal activity pattern and predictable activity are considered influential to observers' preferences (Reynolds \& Braithwaite, 2001). However, some specialized tourist segments may prefer rare and difficultly observable species in Africa (Minin, Fraser, Slotow, \& MacMillan, 2013), which opens an opportunity to broadening flagship marketing campaigns in the Sahara-Sahel.

It has been claimed that utilitarian values are not important to general tourists (Veríssimo et al., 2009), whereas local people put high value in the usefulness of species (Takahashi et al., 2012; Barua et al., 2012). International knowledge of species within the Sahara-Sahel is practically null (Brito et al., 2014), but there is an opportunity to explore this trait further once more scientific knowledge is raised. The use of poisons from desert species for medical research and 
cultural believes, and locally religious representations (e.g. old Animal-Gods in Egypt) can raise the profile of some neglected species, thus contributing to attract funds to its conservation through ecotourism initiatives. The criteria here used serve as a set of guidelines for what attributes should be used to identify flagship fleets that resonate with different audiences. Both tourists and locals need to be considered when assessing such features (Macdonald et al., 2017; Smith et al. 2009). Considering both audiences motivates them to support flagship conservation projects, with implications to broader biodiversity (Barua et al., 2012; Takahashi et al., 2012).

\subsection{Sahara-Sahel flagship fleets}

The variability contained in the most important variables helped shaping fleets. The cluster algorithm grouped several species sharing similar characteristics with flagship appealing into nine flagships fleets, which potentially allows promoting many Sahara-Sahel species in multiflagships campaigns, highlighting the benefits of using flagship fleets to preserve more than just only the most popular species (Veríssimo et al., 2014). From the fleets here identified, largeand small-bodied flagships, retaining many endemic species (e.g. Addax nasomaculatus in fleet A and Acanthodactylus aureus in fleet B; Appendix F), play a key role in the development of strategic marketing campaigns in Sahara-Sahel. Despite the shocking on-going extinction of Sahara-Sahel species (from which several of them were identified as flagships), the world is neglecting reversal conservation measures that would prevent their collapse (Durant et al., 2014; Brito et al., 2018). Hence, these two flagship fleets in particular can be used by local governments to raise the profile of currently overlooked species and to attract international conservation donors, as even less popular species might raise funds in special occasions (Hausmman et al., 2016; Macdonald et al., 2017; Veríssimo et al., 2017). Other ecotourism segments can be attracted as well, which may diversify and enhance tourism operations targeting alternative flagship species (Lindsey et al., 2007; Walpole \& Leader-Williams, 2002). Other identified fleets may be suitable for particular initiatives, for instance groups $\mathrm{H}$ and I are constituted by several bird species, thus being optimal for specific birdwatching and NGO's BirdLife International - conservation campaigns, or for other segments of the society not specialized in desert biodiversity (Di Minin et al., 2013; Root-Bernstein \& Armesto, 2013). Birds were poorly represented in the two most suitable fleets for flagship campaigns (fleets A and $\mathrm{B}$ ) because there are few endemic birds in the Sahara-Sahel with adaptations to desert conditions (Appendix F). However, they might be strong flagship species in other regions rich in endemic birds (e.g. in tropical islands; Veríssimo et al., 2009). No single amphibian was identified as suitable flagships for conservation marketing and ecotourism promotion campaigns (fleets A and B), as only two of them are endemic to the region (Appendix F) and none displays adaptations to local conditions (Brito et al., 2016). Amphibians were investigated as candidate flagships in other works (e.g. Bride et al., 2008), presenting restricted opportunities for generalist audiences not primarily interested in observing regional desert endemic species and for amphibian-enthusiasts that wish to observe more species of this taxonomic group in the Sahara-Sahel. However, amphibians may be strong flagships for conservation and ecotourism stakeholders in other regions of the world, where amphibian richness is higher than in arid regions and where amphibian species display several adaptations to local conditions (e.g., in India; Kanavagel et al., 2017).

\subsection{Flagship hotspots in the Sahara-Sahel}

This was the first study mapping flagship hotspots that may attract ecotourists to these regions and that are able to fund conservation programmes targeting flagship species (Santarém \& Paiva, 2015; Walpole \& Leader-Williams, 2002). Overall, hotspots for large-bodied flagships were mostly fragmented, while hotspots for small-bodied flagship tend to be spatially continuous. This pattern reflects the high regional fragmentation levels of large animal populations (Brito et al., 2014, 2018; Durant et al., 2014) and highlights the need for designing corridors connecting these fragmented patches to protect large-bodied animals (Brito et al., 2016). Although total species richness is larger along the Sahel (Brito et al., 2016), the combined map of hotspots for both flagship fleets suggests that the central Sahara accumulates 
the highest flagship richness (Fig. 3) and that flagship-based observation initiatives probably should be prioritized in this region. Despite the prediction that the Sahel should offer more animal encounters than the Sahara due to local total species richness, it is here demonstrated that the Saharan mountains and waterbodies maximize flagship richness, and that these places may be optimal for flagship-targeted marketing campaigns.

The location of flagship hotspots is broadly coincident with priority conservation areas identified in Sahara-Sahel (Brito et al., 2016). Still, more than half of the flagship hotspots are not currently protected (Fig. 3), which urges the development of protecting schemes towards this unique desert biodiversity, as species occurring in areas of high conservation priority display added value for their conservation marketing (Macdonald et al., 2017). Flagship hotspots in Mauritania, Mali, Niger, and Egypt are particularly poorly protected. By identifying the areas concentrating more flagships, we complement the urgency of preserving these regions and provide local governments with an additional tool to raise funds through flagship species marketing campaigns (Santarém et al., 2018). As most of the species of large- and small-bodied flagship fleets correspond to the most threatened species in the Sahara-Sahel, ecological corridors and transboundary mega conservation areas should be prioritised if these species are to be saved (Brito et al., 2016).

\section{Conclusions}

Evaluating flagship species potential for biological conservation and ecotourism development is an increasing important focus area in many parts of the world, and flagship marketing remains a key fundraising tool for international agencies (e.g. IUCN and United Nations) and NGOs, local governments, and the scientific community. The approach developed here is scalable and replicable worldwide, and the used criteria serve as a set of guidelines for what attributes could and should be used to identify flagship fleets that resonate with different audiences. The methodology has implications for the preservation of several species, as it allows the identification of flagship fleets for conservation marketing and ecotourism promotion in a systematic way. By doing so, flagship-rich regions (flagship hotspots) located in low-income countries can attract international donors able to fund conservation campaigns, hence benefiting even the less popular and charismatic species.

\section{Acknowledgements}

Study partially funded by Rufford Foundation (17893-1), and by AGRIGEN-NORTE-01-0145-FEDER000007, supported by Norte Portugal Regional Operational Programme (NORTE2020), under the PORTUGAL 2020 Partnership Agreement, through the European Regional Development Fund (ERDF). FS, PP, and JCB are supported by Fundação para a Ciência e Tecnologia through grants $\mathrm{PD} / \mathrm{BD} / 132407 / 2017$ and $\mathrm{PD} / \mathrm{BD} / 128492 / 2017$ and contract IF/00459/2013, respectively. JS is supported by Academy of Finland, grant number 272168. We would like to thank BirdLife International and IUCN for providing access to data used in this work. We thank Pedro Tarroso, Chris Fraley and Luca Scrucca for early comments on the use of 'mclust' package. 


\section{References}

AmphibiaWeb. (2017). AmphibiaWeb. Available at https://amphibiaweb.org/ (accessed 3 March 2017).

Andelman, S. J., \& Fagan, W. F. (2000). Umbrellas and flagships: Efficient conservation surrogates or expensive mistakes? Proceedings of the National Academy of Sciences, 97 (11), 5954-5959. doi: 10.1073/pnas.100126797.

Barua, M. (2011). Mobilizing metaphors: the popular use of keystone, flagship and umbrella species concepts. Biodiversity and Conservation, 20, 1427-1440. doi: 10.1007/s10531011-0035-y.

Barua, M., Gurdak., D. J., Ahmed, R. A., \& Tamuly, J. (2012). Selecting flagship species for invertebrate conservation. Biodiveristy and Conservation, 21, 1457-1476. doi: 10.1007/s10531-012-0257-7.

Barua, M., Root-Bernstein, M., Ladle, R. J., \& Jepson, P. (2011). Defining flagship uses is critical for flagship selection: A critique of the IUCN Climate Change Flagship Fleet. Ambio, 40 (4), 431-435. doi: 10.1007/s13280-010-0116-2.

Barua, M., Tamuly, J., \& Ahmed, R. A. (2010). Mutiny or clear sailing? Examining the role of the Asian Elephant as a flagship species. Human Dimensions of Wildlife, 15, 145-160. doi: $10.1080 / 10871200903536176$.

Batt, S. (2009). Human attitudes towards animals in relation to species similarity to humans: a multivariate approach. BioscienceHorizons, 2 (2), 180-190. doi: 10.1093/biohorizons/hzp021.

BirdLife International, \& NatureServe. (2017). Bird species distribution maps of the world. Available at http://www.birdlife.org/datazone/info/spcdownload (accessed 11 November 2017).

Bowen-Jones, E., \& Entwistle, A. (2002). Identifying appropriate flagship species: The importance of culture and local contexts. Oryx, 36, 189-195. doi: $10.1017 / \mathrm{S} 0030605302000261$.

Bride, I. G., Griffiths, R. A., Meléndez-Herrada, A., \& McKay, J. E. (2008). Flying an amphibian flagship: conservation of the Axolotl Ambystoma mexicanum through nature tourism at Lake Xochimilco, Mexico. International Zoo Yearbook, 42, 116-124. doi: 10.1111/j.1748-1090.2008.00044.x.

Brito, J. C., Durant, S. M., Pettorelli, N., Newby, J., Canney, S., Algadafi, W., ... Carvalho, S. B. (2018). Armed conflicts and wildlife decline: Challenges and recommendations for effective conservation policy in the Sahara-Sahel. Conservation Letters, 11, 1-13. doi: 10.1111/conl.12446.

Brito, J. C., Godinho, R., Martínez-Freiría, F., Pleguezuelos, J. M., Rebelo, H., Santos, X., ... Carranza, S. (2014). Unravelling biodiversity, evolution and threats to conservation in the Sahara-Sahel. Biological Reviews, 89, 215-231. doi: 10.1111/brv.12049.

Brito, J. C., Tarroso, P., Vale, C. G., Martínez-Freiría, F., Boratyński, Z., Campos, J., ... Carvalho, S. B. (2016). Conservation Biogeography of the Sahara-Sahel: Additional protected areas are needed to secure unique biodiversity. Diversity and Distributions, 22 (4), 371-384. doi: 10.1111/ddi.12416.

Brown, S. (2010). Where the wild brands are: some thoughts on anthropomorphic marketing. Marketing Review, 10(3), 209-224. Available at https://ssrn.com/abstract=2017467 (accessed 20 June 2018).

Chavent, M., Kuentz-Simonet, V., Labenne, A., Liquet, B., \& Saracco, J. (2017a). PCAmixdata: Multivariate Analysis of Mixed Data. R package version 3.1. Available at https://cran.rproject.org/package=PCAmixdata (accessed 13 March 2018).

Chavent, M., Kuentz-Simonet, V., Labenne, A., \& Saracco, J. (2017b). Multivariate Analysis of Mixed Data: The R Package PCAmixdata.

Chavent, M., Kuentz-Simonet, V., \& Saracco, J. (2012). Orthogonal rotation in PCAMIX. Advances in Data Analysis and Classification, 6, 131-146. doi: 10.1007/s11634-0120105-3.

Clucas, B., Mchugh, K., \& Caro, T. (2008). Flagship species on covers of US conservation and 
nature magazines. Biodiversity and Conservation, 17, 1517-1528. doi: 0.1007/s10531008-9361-0.

Di Minin, E., Fraser, I., Slotow, R., \& MacMillan, D. C. (2013). Understanding heterogeneous preference of tourists for big game species: implications for conservation and management. Animal Conservation, 16, 249-258. doi: 10.1111/j.1469-1795.2012.00595.x. Dinerstein, E., Olson, D., Joshi, A., Vynne, C., Burgess, N. D., Wikramanayake, E., ... Kindt, R. (2017). An Ecoregion-Based Approach to Protecting Half the Terrestrial Realm. BioScience, 67 (6), 534-545. doi: 10.1093/biosci/bix014.

Durant, S. M., Pettorelli, N., Bashir, S., Woodroffe, R., Wacher, T., Ornellas, P. de, ... Baillie, J. (2012). Forgotten Biodiversity in Desert Ecosystems. Science, 336 (6087), 1379-1380. doi: 10.1126/science.336.6087.1379.

Durant, S. M., Wacher, T., Bashir, S., Woodroffe, R., De Ornellas, P., Ransom, C., ... Pettorelli, N. (2014). Fiddling in biodiversity hotspots while deserts burn? Collapse of the Sahara's megafauna. Diversity and Distributions, 20, 114-122. doi: 10.1111/ddi.12157.

Ebner, B. C., Morgan, D. L., Kerezsy, A., Hardie, S., Beatty, S. J., Seymour, J. E., ... McAllister, R. R. J. (2016). Enhancing conservation of Australian freshwater ecosystems: Identification of freshwater flagship fishes and relevant target audiences. Fish and Fisheries, 17(4), 1134-1151. doi: 10.1111/faf.12161.

Encyclopedia of Life. (2017). Encyclopedia of Life. Available at www.eol.org (accessed 14 August 2017).

ESRI. (2012). ArcGIS Release 10.1. CA: Redlands.

Fraley, C., Raftery, A. E., Scrucca, L., Murphy, T. B., \& Fop, M. (2017). Package “mclust”. R package version 5.4.

Garnett, S. T., Ainsworth, G.B., Zander, K.K. (2018). Are we choosing the right flagships? The bird species and traits Australians find most attractive. PLOS ONE, 13 (6): e0199253. doi: https://doi.org/10.1371/journal.pone.0199253.

Graham, C. H., \& Hijmans, R. J. (2006). A comparison of methods for mapping species ranges and species richness. Global Ecology and Biogeography, 15 (6), 578-587. doi: 10.1111/j.1466-822x.2006.00257.x.

Hausmann, A., Slotow, R., Fraser, I., Di Minin, E. (2016). Ecotourism marketing alternative to charismatic megafauna can also support biodiversity conservation. Animal Conservation, 20, 91-100. doi: 10.1111/acv.12292.

Home, R., Keller, C., Nagel, P., Bauer, N., \& Hunziker, M. (2009). Selection criteria for flagship species by conservation organizations. Environmental Conservation, 36 (2), 139 148. doi: $10.1017 / \mathrm{S} 0376892909990051$.

Hosni, E. (2000). Strategy for sustainable tourism development in the Sahara. Paris: UNESCO.

IUCN. (2017). The IUCN Red List of Threatened Species, 2017-3. International Union for Conservation of Nature and Natural Resources. Available at http://www.iucnredlist.org/ (accessed 15 November 2017).

IUCN \& UNEP-WCMC. (2018). The World Database on Protected Areas (WDPA). Cambridge, UK: UNEP-WCMC. Available at http://www.protectedplanet.net (accessed 27 August 2018).

Jepson, P., \& Barua, M. (2015). A Theory of Flagship Species Action. Conservation and Society, 13, 95-104. doi: 10.4103/0972-4923.161228.

Jones, K. E., Bielby, J., Cardillo, M., Fritz, S. A., O’Dell, J., Orme, C. D. L., ... Purvis, A. (2009). PanTHERIA: A species-level database of life history, ecology, and geography of extant and recently extinct mammals. Ecology, 90 (9), 2648. doi: 10.1890/08-1494.1.

Joseph, L. N., Maloney, R. F., Watson, J. E. M., \& Possingham, H. P. (2011). Securing nonflagship species from extinction. Conservation Letters, 4 (4), 324-325. doi: 10.1111/j.1755-263X.2011.00174.x.

Kanagavel, A., Eluvathingal, L. M., Parvathy, S., Kotharambath, R., \& Das., S. (2017). Potential flagship species for improving support and garnering attention towards amphibian conservation in the Western Ghats, India, in Das, A. (ed.), Diversity \& Ecology of Amphibians of India, ENVIS Bulletin: Wildlife \& Protected Areas, Volume 19. Dehradun. Wildlife Institute of India, pp. 271-292. 
Kotsiantis, S. B. (2007). Supervised machine learning: A review of classification techniques. Informatica, 31, 249-268.

Lemelin, H., Dawson, J., \& Stewart, E.J. (2012). Last-Chance Tourism: Adapting tourism Opportunities in a changing World. London: Routledge.

Lindsey, P. A., Alexander, R., Mills, M. G. L., Romañach, S., \& Woodroffe, R. (2007). Wildlife Viewing Preferences of Visitors to Protected Areas in South Africa: Implications for the Role of Ecotourism in Conservation. Journal of Ecotourism, 6, 19-33. doi: 10.2167/joe133.0.

Macdonald, E. A., Burnham, D., Hinks, A. E., Dickman, A. J., Malhi, Y., Macdonald, D. W. (2015). Conservation inequality and the charismatic cat: Felis felicis. Global Ecology and Conservation, 3, 851-866. doi: 10.1016/j.gecco.2015.04.006.

Macdonald, E. A., Hinks, A. E., Weiss, D. J., Dickman, A. J., Burnham, D., Sandom, C. J., Malhi, Y., Macdonald, D. W. (2017). Identifying ambassador species for conservation marketing. Global Ecology and Conservation, 12, 204-214. doi: 10.1016/j.gecco.2017.11.006.

Marchese, C. (2015). Biodiversity hotspots: A shortcut for a more complicated concept. Global Ecology and Conservation, 3, 297-309. doi: 10.1016/j.gecco.2014.12.008.

Myhrvold, N. P., Elita, B., Benjamin, C., Sivam, D., Freeman, D. L., \& Ernest, S. K. M. (2015). An amniote life-history database to perform comparative analyses with birds, mammals, and reptiles. Ecology, 96 (11), 3109. doi: 10.1890/15-0846R.1.

Naidoo, R. \& Adamowicz, W. L. (2005). Biodiversity and nature-based tourism at forest reserves in Uganda. Environment and Development Economics, 10, 159-178. doi: 10.1017/S1355770X0400186X.

Pathak, S., Ojha, C., Zevenbergen, C., \& Garg, R. (2017). Ranking of storm water harvesting sites using heuristic and non-heuristic weighing approaches. Water, 9 (9), 710. doi: 10.3390/w9090710.

Reynolds, P. C., \& Braithwaite, D. (2001). Towards a conceptual framework for wildlife tourism. Tourism Management, 22, 31-42. doi: 10.1016/S0261-5177(00)00018-2.

Root-Bernstein, M., \& Armesto, J. (2013). Selection and implementation of a flagship fleet in a locally undervalued region of high endemicity. Ambio, 42 (6), 776-787. doi: 10.1007/s13280-013-0385-7.

Santarém, F., Campos, J. C., Pereira, P., Hamidou, D., Saarinen, J., \& Brito, J. C. (2018). Using multivariate statistics to assess ecotourism potential of water-bodies: A case-study in Mauritania. Tourism Management, 67, 34-46. doi: 10.1016/j.tourman.2018.01.001.

Santarém, F., \& Paiva, F. (2015). Conserving desert biodiversity through ecotourism. Tourism Management Perspectives, 16, 176-178. doi: 10.1016/j.tmp.2015.07.016.

Scrucca, L., Fop, M., Murphy, T. B., \& Raftery, A. E. (2016). mclust 5: Clustering, classification and density estimation using Gaussian finite mixture models. $R$ Journal, 8 , 289-317.

Siddig, A. A. H. (2014). Biodiversity of Sudan: between the harsh conditions, political instability and civil wars. Biodiversity Journal, 5 (4), 545-555. Available at: http://www.biodiversityjournal.com/ (accessed 28 August 2018).

Simberloff, D. (1998). Flagships, umbrellas, and keystones: Is single-species management passé in the landscape era? Biological Conservation, 83 (3), 247-257. doi: 10.1016/S00063207(97)00081-5.

Smith, A. M., \& Sutton, S. G. (2008). The Role of a Flagship Species in the Formation of Conservation Intentions Conservation Intentions. Human Dimensions of Wildlife, 13 (2), 127-140. doi: 10.1080/10871200701883408.

Smith, R. J., Veríssimo, D., Isaac, N. J. B., \& Jones, K. E. (2012). Identifying Cinderella species: uncovering mammals with conservation flagship appeal. Conservation Letters, 5 (3), 205-212. doi: 10.1111/j.1755-263X.2012.00229.x.

Smith, R. J., Veríssimo, D., Leader-Williams, N., Cowling, R. M., Knight, A. T. (2009). Let the locals lead. Nature, 462, 280-281. doi: 10.1038/462280a.

Takahashi, Y., Veríssimo, D., MacMillan, D. C., \& Godbole, A. (2012). Stakeholder perceptions of potential flagship species for the Sacred Groves of the North Western 
Ghats, India. Human Dimensions of Wildlife, 17 (4), 257-269. doi: 10.1080/10871209.2012.675622.

Tryon, R. C. (1939). Cluster analysis: Correlation Profile and Orthometric (Factor) Analysis for the Isolation of Unities in Mind and Personality. Edwards Brothers, Ann Arbor.

Twining-Ward, L. D., Wendy, L., Elisson M. W., \& Mukeshkumar, B. H. (2018). Supporting sustainable livelihoods through wildlife tourism (English). Tourism for Development knowledge series. Washington, D.C.: World Bank Group. Available at http://documents.worldbank.org/curated/en/494211519848647950/Supporting-sustainablelivelihoods-through-wildlife-tourism (accessed 28 August 2018).

Vale, C., Pimm, S. L., \& Brito, J. C. (2015). Overlooked Mountain Rock Pools in Deserts Are Critical Local Hotspots of Biodiversity. PLoS ONE, 10 (2), e0118367. doi: 10.1371/journal.pone.0118367.

Veríssimo, D., Fraser, I., Girão, W., Campos, A. A., Smith, R. J., \& Macmillan, D. C. (2014). Evaluating conservation flagships and flagship fleets. Conservation Letters, 7 (3), 263270. doi: $10.1111 /$ conl.12070.

Veríssimo, D., Fraser, I., Groombridge, J., Bristol, R., \& Macmillan, D. C. (2009). Birds as tourism flagship species: a case study of tropical islands Research methods. Animal Conservation, 12 (6), 549-558. doi: 10.1111/j.1469-1795.2009.00282.x.

Veríssimo, D., MacMillan, D. C., \& Smith, R. J. (2011). Toward a systematic approach for identifying conservation flagships. Conservation Letters, 4, 1-8. doi: 10.1111/j.1755263X.2010.00151.X.

Veríssimo, D., Pongiluppi, T., Santos, M. C. M., Develey, P. F., Fraser, I., Smith, R. J., \& Macmilan, D. C. (2013). Using a systematic approach to select flagship species for bird conservation. Conservation Biology, 28, 269-277. doi: 10.1111/cobi.12142.

Veríssimo, D., Vaughan, G., Ridout, M., Waterman, C., Macmillan, D., \& Smith, R. J. (2017). Increased conservation marketing effort has major fundraising benefits for even the least popular species. Biological Conservation, 211, 95-101. doi: 10.1016/j.biocon.2017.04.018.

United Nations Educational, Scientific, and Cultural Organization (UNESCO). (2003). Towards a strategy for the sustainable development of tourism in the Sahara, in the context of combating poverty. The Sahara of Cultures and People. Paris, France.

UNEP-WCMC., \& IUCN. (2018). Protected Planet: The World Database on Protected Areas (WDPA). Cambridge, UK: UNEP-WCMC and IUCN. Available at: http://www.protectedplanet.net (accessed 21 August 2018).

Waldron, A., Mooers, A. O., Miller, D. C., Nibbelink, N., Redding, D., \& Kuhn, T. S. (2013). Targeting global conservation funding to limit immediate biodiversity declines. Proceedings of the National Academy of Sciences, 110 (29), 1-5. doi: 10.1073/pnas.1221370110.

Walpole, M., L., \& Leader-Williams, N. (2002). Tourism and flagship species in conservation. Biodiversity and Conservation, 11 (3), 43-547. doi: 10.1023/A:1014864708777.

Wright, A. J., Veríssimo, D., Pilfold, K., Parsons, E. C. M., Ventre, K., Cousins, J., ..., McKinley, E. (2015). Competitive outreach in the 21 st century: Why we need conservation marketing. Ocean \& Coastal Management, 115, 41-48. doi: 10.1016/j.ocecoaman.2015.06.029.

Weaver, D. (2001). The Encyclopedia of Ecotourism. Wallingford, UK: CABI Publishing. 
Table 1. Variables used to evaluate the 1144 Sahara-Sahel species to be used in flagship marketing campaigns, their code, description, type (num: numerical; cat: categorical), units, and data sources.

\begin{tabular}{|c|c|c|c|c|}
\hline Variables & Code & Description & Type & Source \\
\hline $\begin{array}{l}\text { Area of } \\
\text { occupancy }\end{array}$ & $\mathrm{AOC}$ & $\begin{array}{l}\text { Area within a species' extent of } \\
\text { occurrence which is occupied in } \\
\text { Sahara-Sahel: Number of half- } \\
\text { degree cells }\end{array}$ & num & $\begin{array}{l}\text { IUCN, 2017; BirdLife } \\
\text { International \& } \\
\text { NatureServe, } 2011\end{array}$ \\
\hline Body size & BSIZE & $\begin{array}{l}\text { Maximum body size (total } \\
\text { length): } \mathrm{cm}\end{array}$ & num & $\begin{array}{l}\text { AmphibiaWeb, 2017; } \\
\text { Jones et al., 2009; } \\
\text { Encyclopedia of Life, } \\
\text { 2017; Myhrvold et al., } \\
\text { 2015; Appendix A }\end{array}$ \\
\hline Body weight & BWEIG & Maximum weight: gr & num & $\begin{array}{l}\text { AmphibiaWeb, 2017; } \\
\text { Jones et al., 2009; } \\
\text { Encyclopedia of Life, } \\
\text { 2017; Myhrvold et al., } \\
\text { 2015; Appendix A }\end{array}$ \\
\hline Morphology & MORPH & $\begin{array}{l}\text { Unique morphological } \\
\text { adaptations to desert } \\
\text { environments: Number of }\end{array}$ & num & $\begin{array}{l}\text { AmphibiaWeb, 2017; } \\
\text { Encyclopedia of Life, } \\
\text { 2017; Appendix A; } \\
\text { expert-knowledge }\end{array}$ \\
\hline Behaviour & BEHAV & $\begin{array}{l}\text { Unique behavioural adaptations } \\
\text { to desert environments: Number } \\
\text { of }\end{array}$ & num & $\begin{array}{l}\text { AmphibiaWeb, 2017; } \\
\text { Encyclopedia of Life, } \\
\text { 2017; Appendix A; } \\
\text { expert-knowledge }\end{array}$ \\
\hline $\begin{array}{l}\text { Colour } \\
\text { number }\end{array}$ & NCOL & Colours in the body: Number of & num & $\begin{array}{l}\text { AmphibiaWeb, 2017; } \\
\text { Encyclopedia of Life, } \\
\text { 2017; Appendix A }\end{array}$ \\
\hline Colour pattern & $\begin{array}{l}\text { COLPA } \\
\mathrm{T}\end{array}$ & $\begin{array}{l}\text { Colour patterns in the body: } \\
\text { uniform; patches; spots; or stripes } \\
\text { (1); pa+sp or pa+st or sp+st (2); } \\
\text { pa+sp+st (3) }\end{array}$ & cat & $\begin{array}{l}\text { AmphibiaWeb, 2017; } \\
\text { Encyclopedia of Life, } \\
\text { 2017; Appendix A }\end{array}$ \\
\hline Conservation & $\mathrm{CS}$ & $\begin{array}{l}\text { Conservation status: NE; DD; } \\
\text { LC; NT; VU; EN; CR; EW }\end{array}$ & cat & IUCN 2017 \\
\hline Endemic & END & $\begin{array}{l}\text { Endemic in the study area: } \\
\text { Yes/No }\end{array}$ & cat & IUCN 2017 \\
\hline Activity & ACTIV & $\begin{array}{l}\text { Activity patterns: diurnal, } \\
\text { nocturnal or cathemeral (active in } \\
\text { both periods of the day) }\end{array}$ & cat & $\begin{array}{l}\text { Jones et al., 2009; } \\
\text { Appendix A; expert- } \\
\text { knowledge }\end{array}$ \\
\hline Seasonality & SEAS & $\begin{array}{l}\text { Annual activity of species that } \\
\text { influences the availability and }\end{array}$ & cat & Appendix A \\
\hline
\end{tabular}


easiness to observe the species:

All-Year round; seasonal

$\begin{array}{lll}\text { Feeding } & \text { FEED } & \begin{array}{l}\text { Feeding habits: Herbivorous; } \\ \text { Frugivorous; Omnivorous; }\end{array}\end{array} \quad \begin{aligned} & \text { Jones et al., 2009; } \\ & \text { Appendix A }\end{aligned}$

Necrophagous; Carnivorous

Cultural use CRM Animal representations in cultural cat Appendix A; expert-

and religious art, and use of knowledge

animal components for medicine:

Yes/No 
Table 2. Correlation coefficients of species traits with the first two axes (Dimension 1 and 779 Dimension 2; highly correlated values are in bold) of the Principal Component Analysis with mixed data (PCAmix), the eigenvalues and the percentage of explained variation of these two axes. See Fig. 1 for the squared loadings of the species traits within the two first rotated axes.

\begin{tabular}{lcc}
\hline \multicolumn{1}{c}{ Species Traits } & Dimension 1 & Dimension 2 \\
\hline Area of occupancy & 0.183 & -0.034 \\
Body size & 0.027 & $\mathbf{0 . 8 4 1}$ \\
Body weight & -0.048 & $\mathbf{0 . 6 9 2}$ \\
Morphology & $\mathbf{0 . 7 4 6}$ & 0.026 \\
Behaviour & $\mathbf{0 . 7 2 1}$ & 0.045 \\
Colour number & 0.005 & -0.163 \\
Colour patterns & 0.111 & 0.012 \\
Conservation & $\mathbf{0 . 4 6 1}$ & $\mathbf{0 . 3 4 1}$ \\
Endemic & $\mathbf{0 . 3 4 3}$ & 0.000 \\
Activity & 0.019 & 0.111 \\
Seasonality & 0.000 & 0.003 \\
Feeding & 0.108 & $\mathbf{0 . 3 7 6}$ \\
Cultural Use & 0.004 & 0.088 \\
\hline Eigenvalue & 2.160 & 2.149 \\
Cumulative variance (\%) & 8.64 & 17.23 \\
\hline
\end{tabular}


Table 3. List of species within flagship fleets suitable for conservation and ecotourism flagship marketing campaigns in the Sahara-Sahel. Indication of the class, taxa, common name, endemic status (END; Sahara or Sahel), IUCN conservation status (CS), and flagship hotspot (numbered by location) where they can be observed (see Fig. S1 for details on the areas considered). Species that are distributed outside the flagship hotspots are signalled (Outside). Species data follow IUCN (2017).

\begin{tabular}{|c|c|c|c|c|c|}
\hline Class & Taxa & Common name & END & CS & Flagship Hotspot \\
\hline \multicolumn{6}{|c|}{ Fleet A - Large-bodied flagships } \\
\hline \multirow{18}{*}{ Mammalia } & Addax nasomaculatus & Addax & Sahara & $\mathrm{CR}$ & 6 \\
\hline & Ammotragus lervia & Barbary sheep & Sahara & VU & $1 ; 7 ; 11 ; 13 ; 14 ; 15 ; 17 ; 19$ \\
\hline & Equus africanus & African wild ass & - & $\mathrm{CR}$ & $1 ; 21$ \\
\hline & Eudorcas rufifrons & Red-fronted gazelle & Sahel & VU & $1 ; 3 ; 4 ; 8 ; 11$ \\
\hline & Gazella cuvieri & Cuvier's gazelle & Sahara & EN & $12 ; 13 ; 16$ \\
\hline & Gazella dorcas & Dorcas gazelle & Sahara & VU & $1 ; 6 ; 7 ; 11 ; 13 ; 15 ; 16 ; 17 ; 19 ; 20 ; 21$ \\
\hline & Gazella leptoceros & Slender-horned gazelle & Sahara & EN & 20 \\
\hline & Giraffa camelopardalis & Giraffe & - & $\mathrm{LC}$ & $3 ; 4$ \\
\hline & Hippopotamus amphibius & Common hippopotamus & - & $\mathrm{VU}$ & 2 \\
\hline & Kobus megaceros & Nile lechwe & - & EN & 2 \\
\hline & Loxodonta africana & African elephant & - & $\mathrm{VU}$ & $1 ; 2 ; 3 ; 4$ \\
\hline & Nanger dama & Dama gazelle & Sahara & CR & $6 ; 7$ \\
\hline & Nanger soemmerringii & Grant's gazelle & - & $\mathrm{VU}$ & 1 \\
\hline & Oryx beisa & Fringe-eared oryx & - & NT & 1 \\
\hline & Oryx dammah & Scimitar-horned oryx & Sahara & EW & 19 \\
\hline & Panthera leo & African lion & - & VU & $2 ; 3 ; 4$ \\
\hline & Syncerus caffer & African buffalo & - & $\mathrm{LC}$ & $2 ; 3$ \\
\hline & Trichechus senegalensis & African manatee & - & $\mathrm{VU}$ & $8 ; 9 ; 10$ \\
\hline \multirow[t]{4}{*}{ Reptilia } & Acanthodactylus spinicauda & Doumergue's fringe-fingered lizard & Sahara & $\mathrm{CR}$ & 13 \\
\hline & Crocodylus niloticus & Nile crocodile & - & $\mathrm{LC}$ & $1 ; 2 ; 21$ \\
\hline & Crocodylus suchus & West-African crocodile & - & $\mathrm{NE}$ & $1 ; 3 ; 4 ; 8 ; 9 ; 10 ; 11$ \\
\hline & Naja nubiae & Nubian spitting cobra & Sahel & $\mathrm{NE}$ & $1 ; 7 ; 19 ; 21$ \\
\hline
\end{tabular}




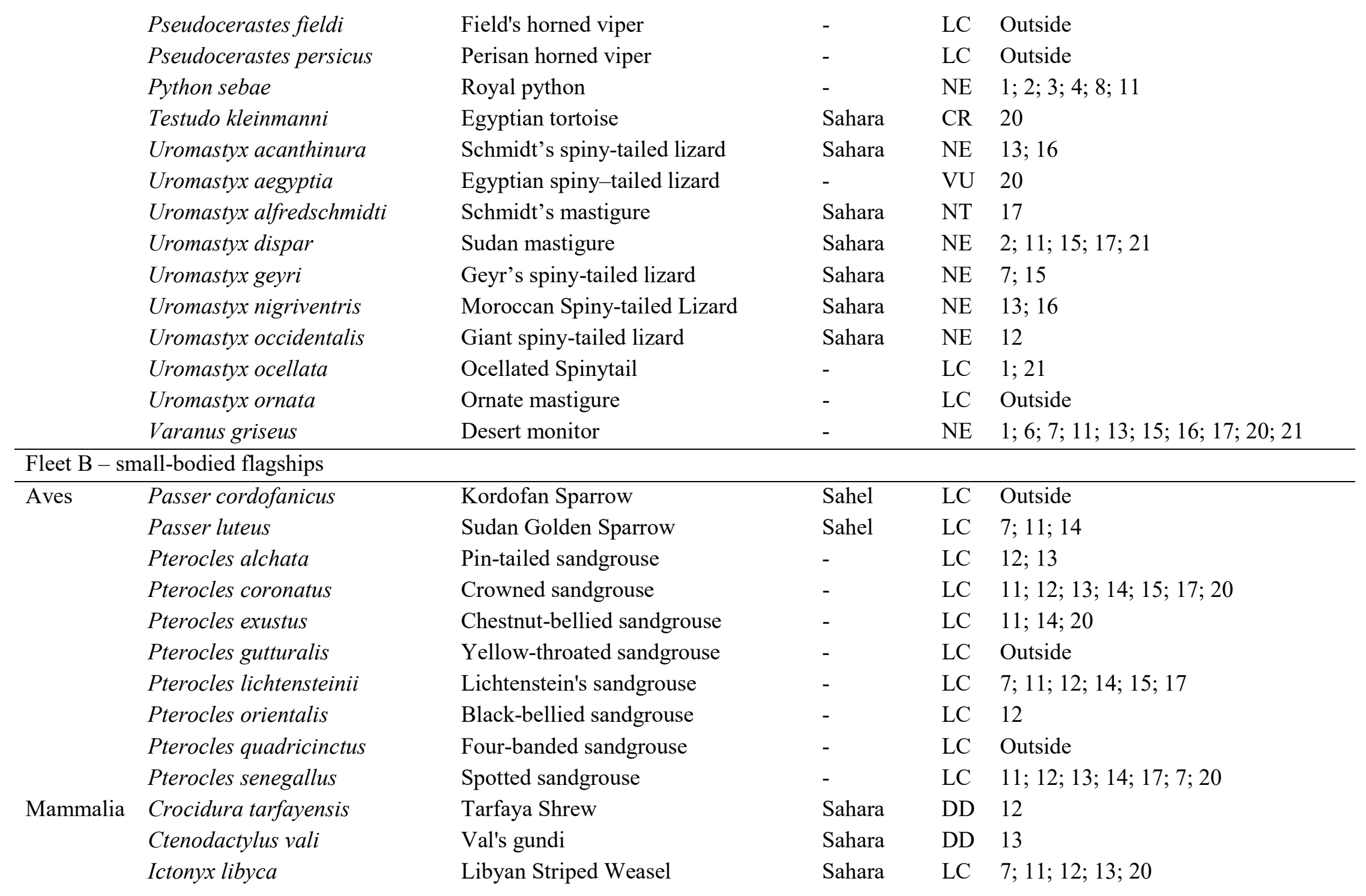


Jaculus jaculus

Jaculus orientalis

Vulpes zerda

Reptilia Acanthodactylus aegyptius

Acanthodactylus aureus

Acanthodactylus boskianus

Acanthodactylus dumerili

Acanthodactylus longipes

Acanthodactylus opheodurus

Acanthodactylus scutellatus

Acanthodactylus taghitensis

Agama boueti

Agama boulengeri

Agama spinosa

Agama tassiliensis

Cerastes cerastes

Cerastes vipera

Chalcides boulengeri

Chalcides delislei

Chalcides humilis

Chalcides sepsoides

Chalcides sphenopsiformis

Dasypeltis sahelensis

Echis coloratus

Echis pyramidum

Eryx jaculus

Leptotyphlops algeriensis

Leptotyphlops boueti
Lesser Egyptian jerboa

Greater Egyptian jerboa

Fennec fox

Egyptian fringe-fingered lizard

Golden fringe-fingered lizard

Bosc's fringe-toed lizard

Duméril's fringe-fingered lizard

Long fringe-fingered lizard

Arnold's fringe-fingered lizard

Nidua fringe-fingered lizard

Taghit's fringe-toed lizard

Bouet's agama

Boulenger's agama

Spiny Agama

Tassili agama

Desert horned viper

Sahara sand viper

Boulenger's feylinia

De l'Isle's wedge-snouted skink

Ragazzi's bronze skink

Wedge-snouted skink-

Duméril's wedge-snouted skink

Sahel egg eater

Palestine saw-scaled viper

Egyptian saw-scaled viper

Javelin Sand Boa

Beaked thread-snake

Bouet's worm snake

$\begin{array}{lll}- & \text { LC } & 7 ; 11 ; 12 ; 15 ; 17 ; 20 \\ - & \text { LC } & 20 \\ \text { Sahara } & \text { LC } & 7 ; 11 ; 12 ; 13 ; 14 ; 15 ; 17 ; 20 \\ \text { Sahara } & \text { NE } & 20 \\ \text { Sahara } & \text { NE } & 12 \\ - & \text { NE } & 7 ; 11 ; 12 ; 13 ; 14 ; 15 ; 17 ; 20 \\ \text { Sahara } & \text { NE } & 11 ; 12 ; 13 ; 14 \\ \text { Sahara } & \text { NE } & 11 ; 12 ; 13 ; 14 ; 15 ; 17 ; 20 \\ - & \text { LC } & \text { Outside } \\ \text { - } & \text { NE } & 1 ; 7 ; 11 ; 13 ; 14 ; 15 ; 17 ; 19 \\ \text { Sahara } & \text { DD } & 12 \\ \text { Sahel } & \text { LC } & 7 ; 11 ; 14 \\ \text { Sahara } & \text { LC } & 11 \\ - & \text { LC } & 20 \\ \text { Sahara } & \text { LC } & 7 ; 14 ; 15 ; 17 \\ - & \text { NE } & 11 ; 12 ; 13 ; 14 ; 15 ; 17 ; 20 \\ - & \text { LC } & 11 ; 12 ; 13 ; 14 ; 15 ; 17 ; 20 \\ \text { Sahara } & \text { NE } & 12 ; 13 ; 15 ; 17 \\ \text { Sahel } & \text { LC } & 7 ; 11 ; 14 \\ \text { Sahara } & \text { NE } & 20 \\ \text { Sahara } & \text { LC } & 20 \\ \text { Sahara } & \text { LC } & 12 \\ \text { Sahel } & \text { NE } & 7 \\ - & \text { NE } & 20 \\ - & \text { LC } & 7 ; 11 ; 12 ; 14 ; 15 \\ \text { - } & \text { NE } & 20 \\ \text { Sahara } & \text { NE } & 7 ; 11 ; 12 \\ \text { Sahel } & \text { NE } & \text { Outside } \\ & & \end{array}$




\begin{tabular}{|c|c|c|c|c|}
\hline Leptotyphlops cairi & Two-coloured blind snake & Sahara & $\mathrm{NE}$ & 20 \\
\hline Leptotyphlops macrorhynchus & Beaked blind snake & - & NE & 20 \\
\hline Leptotyphlops nursii & Nurse's blind snake & - & $\mathrm{NE}$ & Outside \\
\hline Mauremys leprosa & Mediterranean Turtle & - & NE & $12 ; 13$ \\
\hline Mesalina rubropunctata & Red-spotted lizard & Sahara & NE & $7 ; 11 ; 12 ; 14 ; 15 ; 17 ; 20$ \\
\hline Philochortus lhotei & Lhote's shield-backed ground lizard & Sahel & NE & $7 ; 15$ \\
\hline Pristurus adrarensis & Adrar semaphore gecko & Sahara & DD & 11 \\
\hline Pseudotrapelus sinaitus & Sinai agama & - & NE & 20 \\
\hline Ptyodactylus guttatus & Sinai fan-fingered gecko & - & NE & 20 \\
\hline Ptyodactylus hasselquistii & Yellow fan-fingered gecko & - & NE & 20 \\
\hline Ptyodactylus oudrii & Oudri's fan-footed gecko & - & $\mathrm{LC}$ & $12 ; 13$ \\
\hline Ptyodactylus ragazzi & Ragazzi's fan-footed gecko & - & NE & $11 ; 14 ; 15 ; 17$ \\
\hline Ptyodactylus siphonorhina & Sinai fan-fingered gecko & Sahara & $\mathrm{NE}$ & $11 ; 14$ \\
\hline Scincopus fasciatus & Peters' banded skink & Sahel & DD & $7 ; 12 ; 13$ \\
\hline Scincus albifasciatus & Senegal Sandfish & Sahara & $\mathrm{NE}$ & $11 ; 12 ; 13$ \\
\hline Scincus scincus & Sandfish skink & - & $\mathrm{NE}$ & $13 ; 14 ; 15 ; 17 ; 20$ \\
\hline Stellagama stellio & Starred Agama & - & $\mathrm{LC}$ & 20 \\
\hline Stenodactylus petri & Egyptian sand gecko & Sahara & $\mathrm{NE}$ & $7 ; 11 ; 12 ; 14 ; 15 ; 17 ; 20$ \\
\hline Stenodactylus stenodactylus & Elegant Gecko & Sahara & $\mathrm{NE}$ & $7 ; 11 ; 12 ; 14 ; 15 ; 17 ; 20$ \\
\hline Trapelus boehmei & Desert agama & Sahara & $\mathrm{LC}$ & $11 ; 12$ \\
\hline Trapelus mutabilis & Desert agama & Sahara & NE & $7 ; 13 ; 15 ; 17$ \\
\hline Trapelus pallidus & Pallid agama & - & $\mathrm{NE}$ & 20 \\
\hline Trapelus schmitzi & Schmitz' agama & Sahara & DD & $15 ; 17$ \\
\hline Trapelus tournevillei & Sahara agama & Sahara & $\mathrm{LC}$ & 13 \\
\hline Tropiocolotes algericus & Algerian sand gecko & Sahara & NE & $11 ; 12 ; 13$ \\
\hline Tropiocolotes bisharicus & Bishari pigmy gecko & Sahara & $\mathrm{NE}$ & Outside \\
\hline Tropiocolotes steudeneri & Algerian sand gecko & Sahara & NE & $7 ; 15 ; 17 ; 20$ \\
\hline Typhlops etheridgei & Mauritanian Blind Snake & Sahara & DD & 11 \\
\hline
\end{tabular}




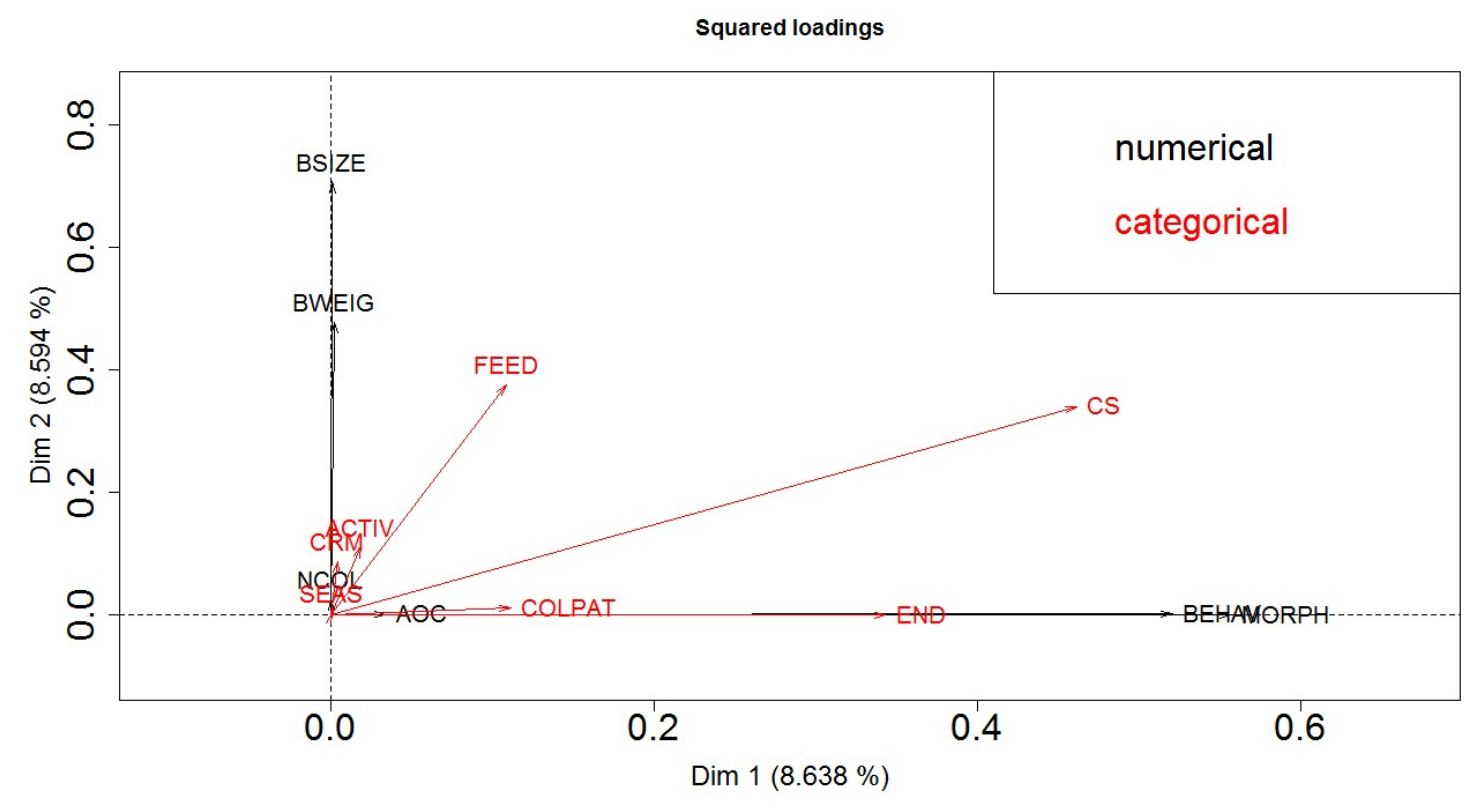

Fig. 1. Squared loadings of species traits within the first and second axes (Dim 1 and Dim 2) of the rotated PCA with mixed data. The PCA is performed based on six numerical variables and seven categorical variables. See Table 2 for the correlation coefficients of the variables within the two rotated axes. 


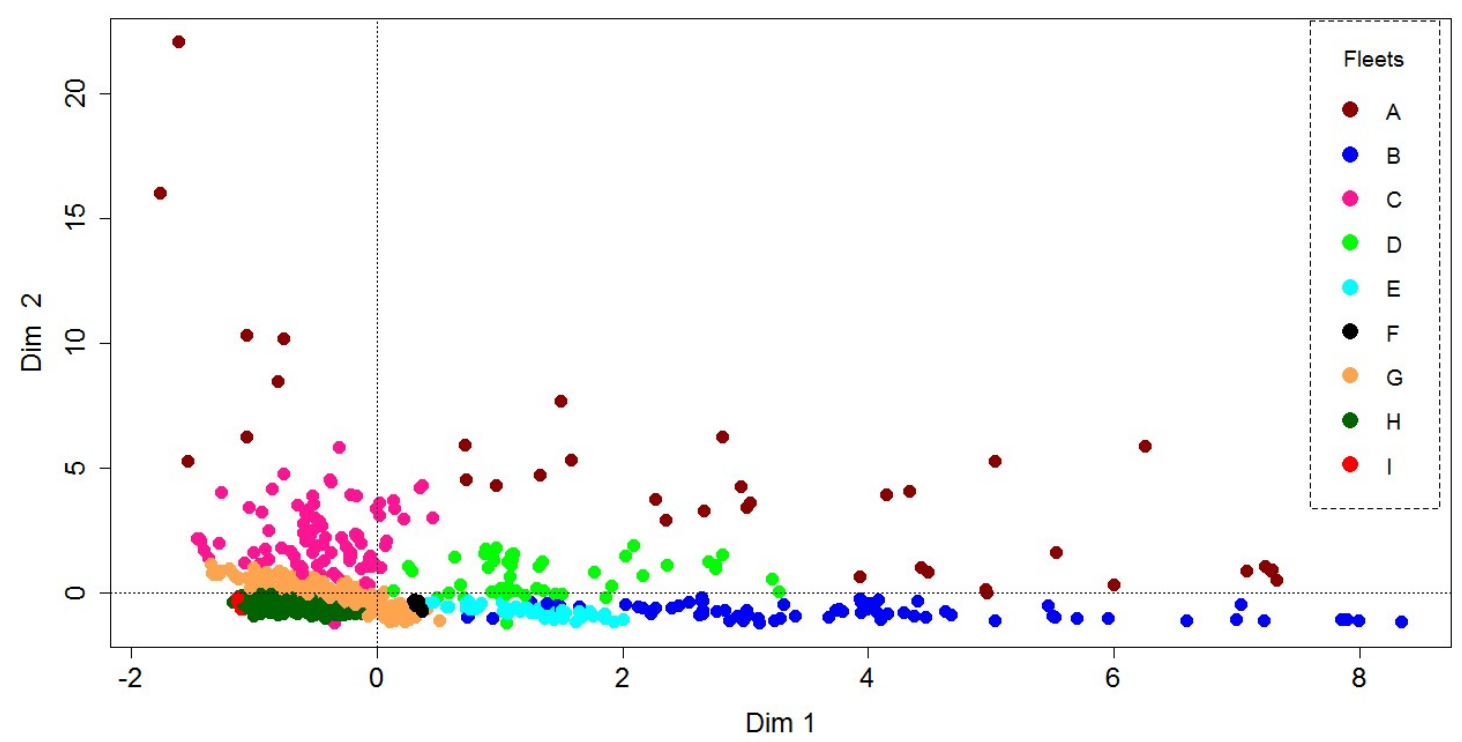

Fig. 2. Flagship fleets identified by the Bayesian Information Criterion (BIC) applied to the two first rotated axes (Dim 1 and Dim 2) of Principal Component Analysis with mixed data (PCAmix; see Appendix B for methodological details). Large-bodied flagships (brown points) and small-bodied flagships (dark blue points) were used to map flagship hotspots. 

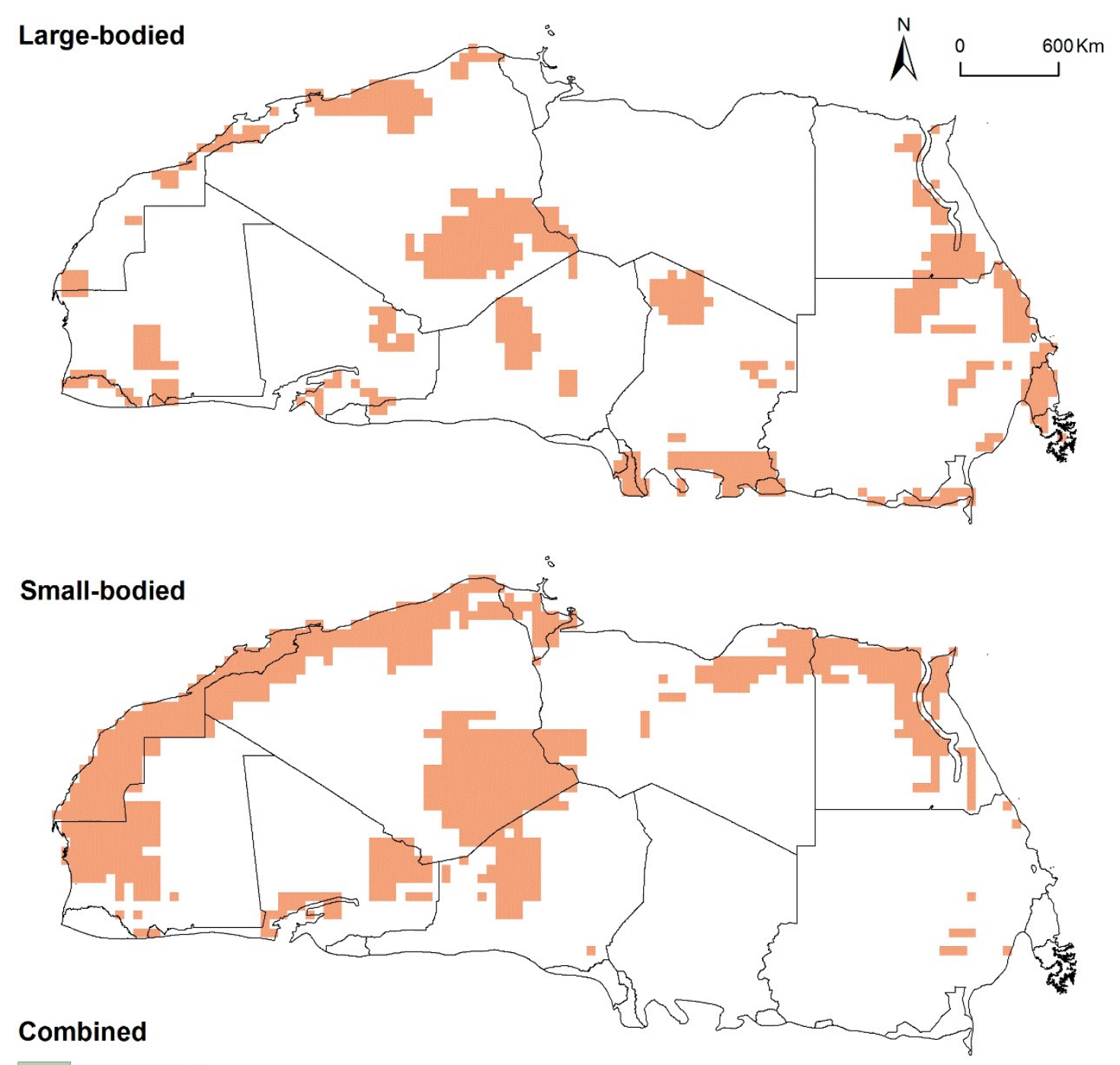

Fig. 3. Flagship Hotspots of large-bodied flagship fleets (above), small-bodied flagship fleets (centre), and both fleets combined (bottom) in the Sahara-Sahel. Areas with higher flagship richness are depicted in orange (above and centre) and dark red (bottom). The extent of Flagship Hotspots covered by current protected areas network (UNEP-WCMC \& IUCN, 2018) is indicated by the Protected Areas polygons in the combined map. See Appendix C for the names of the areas. 